\title{
Guidelines for allergy prevention in Hong Kong
}

\author{
Alson WM Chan *, June KC Chan, Alfred YC Tam, TF Leung, TH Lee
}

\section{A B S T R A C T}

Allergic diseases are a global problem. Mothers are advised to enjoy a healthy diet with no restrictions during pregnancy and lactation, as prophylactic dietary restriction is unlikely to reduce the development of atopic disease. Breastfeeding is recommended for the first 6 months of the newborn's life. Atopic eczema has been shown to be significantly reduced in high-risk infants fed a hydrolysed formula compared with standard cow's milk formula. Complementary food is also recommended for infants over 4 months if they are developmentally ready. Various environmental factors may influence the prevalence and course of allergic diseases. There is a strong epidemiological association between air pollution from traffic and allergies. Smoking is also a significant risk factor. Home dampness and visible mold are associated with recurrent wheeze and asthma. House dust mite is a possible cause of asthma. Lifestyle factors also play a role. Obesity shows a clear relationship with asthma and eczema. Stressful life events may increase the risk of atopic disease. Immunotherapy has been shown to be effective. It reduces new sensitisations and prevents progression of allergic rhinitis to asthma. Summary of the above recommendations are presented.

Hong Kong Med J 2016;22:279-85

DOI: $10.12809 / \mathrm{hkmj} 154763$
${ }^{1}$ AWM Chan *, FHKCPaed, FHKAM (Paediatrics)
${ }^{2}$ JKC Chan, RD (USA), MSC
${ }^{1}$ AYC Tam, FHKCPaed, FHKAM (Paediatrics)
${ }^{3}$ TF Leung, MD, FHKAM (Paediatrics)
${ }^{2}$ TH Lee, ScD (Cantab), FRCP (Lond)
Department of Paediatrics and Adolescent Medicine, The University of Hong Kong, Pokfulam, Hong Kong
${ }^{2}$ Allergy Centre, Hong Kong Sanatorium \& Hospital, Happy Valley, Hong Kong
${ }_{3}^{3}$ Department of Paediatrics, The Chinese University of Hong Kong, Shatin, Hong Kong

This guideline was presented in part at the Symposium on Allergy Prevention that was co-hosted by the Hong Kong Institute of Allergy \& the Hong Kong Society for Paediatric Immunology, Allergy and Infectious Diseases, 17 September 2015, Hong Kong.

* Corresponding author: awmc@hku.hk

\section{Introduction}

There has been a continuous rise over the last 50 years in the prevalence of allergic diseases in both developed and developing countries. The situation is especially dramatic in children. Up to $40 \%$ to $50 \%$ of schoolchildren are now sensitised to one or more common allergens. The growing burden of allergic diseases has been recognised as a new pandemic of the 21 st century. ${ }^{1}$

It has long been acknowledged that genetically predisposed children usually develop various allergic diseases in the typical evolution described as 'Allergic March'. Cow's milk and food are the first allergens that infants encounter soon after birth. Their allergies then progress from the gut and skin to the respiratory tract when they grow older and come into contact with more environmental allergens. Prevention strategies applied during infancy or early childhood have been shown to stop the manifestations of allergy and its 'marching' from gut to skin and to airway. ${ }^{2}$

Recent studies have shown that induction of immune tolerance is the key to success in allergy prevention. Early food allergen introduction between 4 and 6 months leads to better immune tolerance. ${ }^{3}$ New evidence is also showing the association of allergy with various environmental and lifestyle factors that might be amenable to manipulation.

As the burden of allergic diseases has been increasing and the concept of allergy has been changing quickly over the last few years, there is a need to develop updated guidelines for allergy prevention.

\section{Epidemiology of allergic diseases in Hong Kong children}

Allergic diseases constitute a major health problem worldwide, with asthma as one of the most common chronic diseases of childhood. The populationbased International Study of Asthma and Allergies in Childhood (ISAAC) determined that about one tenth of secondary schoolchildren have asthma and $15 \%$ have atopic dermatitis. About one third of Hong Kong children aged 6 to 7 years suffer from rhinitis. ${ }^{4}$ The phase-2 ISAAC confirmed aeroallergen sensitisation as a major risk factor for childhood allergies, ${ }^{5}$ but this relationship varied substantially among populations and increased with economic development.

There are limited data on the prevalence and risk factors for atopic disorders among Asian preschool children. Using an ISAAC-based 


\section{香港預防過敏指引}

\section{陳偉明、陳勁芝、譚一翔、梁廷勳、李德康}

過敏性疾病是一個全球性健康問題。孕婦在懷孕和哺乳期間應有健康 的飲食習慣, 肜須特別戒口, 皆因為了預防或減低過敏症風險而戒口 並不能減少過敏症。建議在嬰兒六個月前以母乳哺育, 高危嬰兒進食 水解配方奶粉比較用傳統牛奶配方會有較低的濕疹病發率。隨着身體 機能成熟, 幼兒可在四個月大開始進食半固體或固體食物。多種環境 因素可以影響過敏性疾病的病情和患病率。由交通帶來的空氣污染與 過敏症流行病學關係密切, 吸煙亦是引致過敏症的重要因素。家居潮 濕的環境而產生霉斑與反復喘鳴及哮喘發作相關。室內塵蟎亦可能引 致哮喘。生活習慣與過敏性疾病也息息相關。肥胖與哮喘和濕疹有顯 著關係, 生活壓力亦可能增加過敏風險。免疫療法對防治過敏性疾病 有功效, 它可以減少新的過敏產生, 亦能預防由過敏性鼻炎 (鼻敏 感）演變成哮喘。本文把上述建議作進一步探討。 questionnaire, we reported the prevalence of 'ever' and 'current' wheeze among Hong Kong children aged 2 to 6 years to be $16.7 \%$ and $9.3 \%$, respectively. Consistent with our earlier report for older Chinese children, ${ }^{7}$ the use of foam pillow and gas as the cooking fuel in infancy were significant risk factors for current wheeze in these young children.

The incidence rates of asthma and allergies have been increasing in many developed countries. Our phase-3 ISAAC nonetheless found a reduced asthma prevalence over an 8-year period among Hong Kong secondary schoolchildren. ${ }^{8}$ The prevalence of asthma ever, wheeze ever, and current wheeze was also similar in local children aged 6 to 7 years between 1995 and 2001, although there was a significant increase in lifetime and current rhinitis, current rhinoconjunctivitis, and lifetime eczema during this period. ${ }^{9}$

A territory-wide questionnaire study investigated the prevalence of adverse food reactions (AFR) among local children attending 21 randomly selected nurseries and kindergartens in 2004/2005. ${ }^{10}$ The prevalence rates of parent-reported AFR and parent-reported, doctor-diagnosed AFR were $8.1 \%$ and $4.6 \%$, respectively. The occurrence of AFR in these pre-schoolers adversely affected their parents' quality of life. ${ }^{11}$ Shellfish was the most important food for AFR, followed by egg, peanut, cow's milk, beef, tree nuts, and fish. Another local study supported these findings. ${ }^{12}$ These figures suggested similar epidemiology and spectrum of food allergy between our Chinese and Caucasian children. Because questionnaire data may be subject to biased reporting, we also collected data for probable food allergy that was defined by the presence of suggestive clinical features and either positive skin prick test or in-vitro allergen-specific immunoglobulin (Ig) E assays. ${ }^{13}$ The prevalence of probable food allergy was $2.8 \%$ in our primary schoolchildren. ${ }^{14}$
In another more recent study, our group adopted the same sampling strategy and methodology to investigate longitudinal changes in food allergy prevalence among Chinese preschool children. ${ }^{15}$ The prevalence of parent-reported AFR was $9.7 \%$, but there was no change in parentreported, doctor-diagnosed AFR. When adjusted for maternal education as a covariate, the prevalence of parent-reported AFR was static whereas that of parent-reported, doctor-diagnosed AFR significantly decreased during this 9 -year period. ${ }^{15}$

\section{Maternal diet during pregnancy}

It is universally recommended for all mothers to eat a healthy diet without restriction during pregnancy. Prophylactic dietary restriction of potent food allergens should not be encouraged. ${ }^{16}$

During the first trimester, higher maternal intake of peanut, milk, and wheat is associated with a significant reduction in the risk of developing a peanut allergic reaction, asthma and allergic rhinitis, and atopic dermatitis in mid-childhood, respectively. ${ }^{17}$ In addition, a restrictive diet may have adverse effects on maternal or fetal nutrition.

Maternal consumption of fruits and vegetables, fish, long-chain omega- 3 fatty acids, a good ratio of omega-3-to-omega- 6 fatty acids, and milk fat during pregnancy is associated with a lower prevalence of allergy. The consumption of fruits and vegetables is beneficial for their antioxidants and natural prebiotics that may have prophylactic properties by promoting a more diverse microbiota and consequently a positive effect on fetal immune development. ${ }^{18}$ The consumption of fish during pregnancy has a protective effect against the development of atopic diseases in children. The current German guidelines recommend that fish consumption is encouraged in pregnancy. ${ }^{19}$

\section{Maternal diet during lactation}

Studies that examined the effect of food avoidance during lactation have been criticised for methodological shortcomings and small sample size, and more research is required in this area. Currently, there is no evidence to support maternal dietary avoidance of potent food allergens while breastfeeding as a means of preventing development of food allergy in their children. ${ }^{16}$

\section{Breastfeeding}

For all infants, breastfeeding is recommended for at least the first 4 to 6 months of life.${ }^{19-21}$ Breastfeeding has many health benefits for both mothers and infants, and the World Health Organization recommends that infants should be exclusively breastfed for the first 6 months of life. Evidence suggests that exclusive breastfeeding for at least 
3 months reduces the risk of atopic dermatitis in infancy although data are weaker for other allergic diseases. ${ }^{22}$ When compared with conventional cow's milk formula, breast milk has a significant protective effect against atopic dermatitis and wheezing in the first 2 years of life and might play a role in the development of oral tolerance. ${ }^{23}$

\section{Formula feeding}

The GINI (German Infant Nutritional Intervention) study's 15 -year data show that in high-risk infants, compared with standard cow's milk formula, the consumption of extensively hydrolysed casein formula is associated with a reduced cumulative incidence of eczema and allergic rhinitis, as well as a reduced prevalence of eczema and asthma in adolescence. The consumption of partially hydrolysed whey formula is associated with a reduced cumulative incidence of eczema and prevalence of allergic rhinitis in adolescence. On the contrary, there is no significant benefit for consumption of extensively hydrolysed whey formula, indicating the degree of hydrolysis alone does not fully explain the preventive power of a formula and further research will be needed in this area. ${ }^{24}$ There is no evidence for the use of soy formula or goat formula in the prevention of food allergies and amino acid formula has not been well studied.

\section{Introduction of complementary foods}

Introduction of complementary foods is recommended for infants aged over 4 months. There is no benefit in delaying introduction beyond 4 to 6 months in order to prevent allergic diseases. ${ }^{25}$ An infant diet consisting of high levels of fruits, vegetables, and home-prepared foods is associated with less food allergy by the age of 2 years. ${ }^{26}$ When introducing complementary foods, consideration of developmental readiness, parental needs, nutritional needs, and behavioural risks of the infant should be made.

\section{Introduction of potential food allergens}

There is emerging evidence that delaying solid food introduction beyond 6 months, especially those containing potent food allergens, may increase the risk of food allergy or eczema. ${ }^{23}$ Data from a Finnish cohort study indicate that late introduction of potatoes, oats, rye, wheat, meat, fish, and eggs was significantly and directly associated with sensitisation to food allergens, ${ }^{27}$ while late introduction of potatoes, rye, meat, and fish was associated with inhalant allergen sensitisation. Recently, the LEAP (Learning Early About Peanut allergy) study has demonstrated that consumption of peanuts within the first year of life in high-risk infants can lower the chance of peanut allergy compared with avoidance until the age of 5 years. ${ }^{28}$ Another randomised controlled trial found that infants exposed to whole egg powder daily starting at 4 to 8 months had higher egg-specific IgG4 levels compared with a control group..$^{29}$ Furthermore, introduction of fish before 9 months of age is associated with a lower risk of eczema and is recommended by one of the national guidelines. ${ }^{19}$

At present, there is insufficient evidence to recommend early introduction of all potential food allergens. The current recommendation is neither to withhold nor encourage early introduction of any food allergens..$^{19-21}$ Breastfeeding during the period of solid food introduction is likely to attenuate any allergic response. ${ }^{33}$

\section{Environmental influence on allergy \\ Air pollution}

It has long been recognised that atmospheric air pollution is associated with exacerbation of asthma and allergic rhinitis, and is blamed for surges in hospital admissions for asthma. In the past decade, much epidemiological evidence has linked exposure to air pollution from traffic, especially diesel exhaust particulates, oxides of nitrogen, and soot (carbon dust) to the development of asthma, allergic sensitisation, and compromised lung function. ${ }^{30}$ Another report investigated the relationship between traffic-associated pollution and eczema in children aged 6 years. Eczema prevalence was significantly higher in children who lived in traffic-related, highly polluted areas. ${ }^{31}$

Mechanisms implicated in the association between air pollution and paediatric asthma include the up-regulation of allergic immune responses, activation of oxidative stress pathways, and epigenetic regulation.

\section{Tobacco smoke}

The effect of both active smoking (AS) and passive smoking (PS) on the development of allergic diseases in adults and children has been recently reviewed..$^{32}$ When all studies including cohort, case-control, and cross-sectional studies were included, allergic rhinitis was not associated with AS, but was associated with PS. Allergic dermatitis was associated with both AS and PS. In children and adolescents in particular, allergic rhinitis was associated with both AS and PS, as was allergic dermatitis. Among cohort studies, PS was significantly associated with an increased risk of food allergy in children and adolescents. From these studies, it can be seen that the effect of tobacco smoke is more severe in children and adolescents compared with adults. In countries with high smoking prevalence, the authors estimated that $14 \%$ of allergic rhinitis cases and $13 \%$ of allergic 
dermatitis are attributable to AS. ${ }^{33}$

The European Community Respiratory Health Survey has reported the effects of PS from fetus to adulthood. ${ }^{33,34}$ Maternal smoking during pregnancy, maternal smoking, or both parents smoking was more likely to be associated with asthma symptoms in offspring, even after accounting for smoking behaviour, exposure to PS, and occupational exposure. ${ }^{32}$ Total IgE levels were higher in smokers than non-smokers. The smokers were more likely to be sensitive to house dust mite (HDM) but not to cat dander or grass pollen. On the other hand, PS was significantly associated with bronchial responsiveness to methacholine and with current asthma.

\section{Indoor environment}

The meta-analysis from eight European birth cohorts showed that exposure to visible mold and/ or dampness during the first 2 years of life was associated with an increased risk of developing asthma, including early asthma symptoms and asthma later in childhood. ${ }^{35}$ In another study, high visible mold in the home environment was also associated with recurrent wheeze at the age of 3 years and a positive Asthma Predictive Index. ${ }^{36}$ Other risk factors at home that have been reported to be associated with recurrent wheezing include use of foam pillow and exposure to gas cooking fuel. ${ }^{6}$

Another recent review and meta-analysis reported an overall $25 \%$ reduction in doctordiagnosed asthma and recurrent wheeze in children exposed to a farming environment. ${ }^{37}$ The mechanism of effect of farm exposure on allergy development has been thought to be related to raw farm milk consumption and/or exposure to a wider range of micro-organisms in the farm, and its resultant gut microbiome.

Allergen exposure, especially to HDM allergen, has been implicated as a possible cause of allergic asthma. Many studies have attempted to prevent allergies and asthma by controlling HDM and other allergens in the home environment. A recent meta-analysis $^{38}$ reported a significant reduction in physician-diagnosed asthma as a result of interventions to reduce exposure to HDM (relative risk $[R R]=0.74 ; 95 \%$ confidence interval $[\mathrm{CI}], 0.58$ 0.95). There was, however, no significant effect on parent-reported wheeze $(\mathrm{RR}=0.95 ; 95 \% \mathrm{CI}, 0.78$ 1.15). This may suggest that reduced exposure to HDM prevents the more severe form of asthma but not the more common and milder forms that may not be allergic in origin. A pooled analysis of over 22000 children participating in 11 European birth cohorts concluded that there was neither an increase nor reduction in the risk of asthma or allergic rhinitis in children in relation to pet ownership in early life..$^{39}$ The situation with other allergens is not clear.
In conclusion, dampness, visible mold, and HDM are important indoor factors in the development of allergic disease. The control of these factors is likely to lead to a lesser chance of development of allergic disease including asthma. Although a farming environment is known to be associated with a lower incidence of allergy, recommendation is still difficult and awaits further analysis of the mechanism of action.

\section{Viral respiratory infections}

Early viral respiratory infections have been implicated in the development of asthma and other respiratory allergies later in life. Human rhinovirus and respiratory syncytial virus have been found to be associated with a markedly higher risk of persistent wheezing at 6 years of age. ${ }^{40}$ Another study of over 2000 children confirmed an increased risk of newonset wheeze at the age of 2 years in those suffering from childhood infections like common cold, fever, and diarrhoea during the first 3 months of life. ${ }^{41}$ Preventive strategies, apart from general infection control measures, consist of giving respiratory syncytial virus Ig to vulnerable infants. ${ }^{42}$

\section{Lifestyle}

\section{Overweight and obesity}

A healthy lifestyle with a balanced calorie intake and expenditure should be encouraged. A recent meta-analysis has revealed that being overweight poses an increased risk of asthma. This risk is further elevated in obese subjects with a clear doseresponse relationship between body mass index and risk of asthma. ${ }^{43}$ European birth cohorts recruiting more than 12000 subjects have demonstrated that a rapid rise of body mass index in the first 2 years of life increased the risk of asthma up to 6 years old (hazard ratio $=1.3 ; 95 \% \mathrm{CI}, 1.1-1.5) .{ }^{4}$ There is also a significant association between overweight/obesity and eczema. ${ }^{45}$ Excessive body weight should be avoided to help prevent the development of allergic diseases.

\section{Psychosocial factors}

A growing number of studies indicate that experiencing stressful life events (eg parental separation, death of a parent, parental unemployment), either during pregnancy or in early childhood, increases the risk of subsequent atopic diseases. ${ }^{46}$ Early therapeutic counselling may represent a preventive approach in these children.

\section{Pharmaceuticals}

A population-based study of over 16000 Finnish patients revealed an increased risk of cow's milk allergy associated with maternal/child use of 
antibiotics in a dose-related manner. ${ }^{47}$ Further studies are needed to confirm this observation in other populations. At present, no causal relationship has been established between the use of pharmaceuticals and the development of atopic disease.

\section{Probiotics}

Probiotics have been shown in some studies to prevent the development of eczema. ${ }^{48}$ Nonetheless, more studies are required to confirm their efficacy and most allergy guidelines do not make any recommendations about probiotics.

\section{Vaccinations}

There is no evidence to show that vaccination practices have any adverse effect on the incidence of allergic diseases in population-based cohort studies ${ }^{49}$ It is advised that children are vaccinated according to the current recommended schedule, including high-risk children.

\section{Vitamin D}

Clinical studies have produced conflicting results with regard to the relevance of vitamin $D$ in the development of allergic diseases. There are currently insufficient data to support any recommendation.

\section{Immunotherapy}

Immunotherapy, both subcutaneous and sublingual, is an important tool in the secondary prevention of allergic diseases. There is evidence that immunotherapy of allergic rhinitis can prevent the subsequent progression to asthma. ${ }^{50}$ It can also reduce new sensitisations in patients monosensitised to aeroallergens and has an impact on the natural history of respiratory allergies. ${ }^{51}$

\section{Conclusions}

The strengthening of immune tolerance is the current focus of allergy prevention. In addition to allergen avoidance, further studies are now underway to investigate how immune tolerance to different allergens can be boosted, while minimising sensitisation and further allergic responses. In general, the greater the exposure to environmental and commensal microbes in terms of diversity and quantity during infancy and early childhood, the greater the development of immune tolerance and less atopic tendency later on, even in those who are genetically susceptible. ${ }^{52}$ The allergy prevention measures we recommend are summarised in the Box. For those who are at higher risk of allergy development, that is those with a family history of allergy or the presence of several risk factors (eg breastfeeding for $<6$ months; maternal AS or PS
BOX. Allergy prevention measures

1. No unnecessary diet restriction during pregnancy and
lactation
2. Breastfeeding in the first 6 months of life
3. Consider hydrolysed formula milk in high-risk infants if
exclusive breastfeeding is not feasible
4. Introduce complementary food from 4 to 6 months of
age when developmentally ready
5. Control air pollution
6. Avoid both active or passive smoking
7. Control indoor air quality
8. Control weight and avoid obesity
9. Avoid excessive psychological stress
10. Receive immunisations as recommended
11. Judicious use of antibiotics
12. Early treatment and control of atopic diseases

during pregnancy; delivered by caesarean section), it is recommended that they observe the allergy prevention measures and consult a medical doctor early should they develop clinical features of allergic diseases. Besides recommendations on a personal level, the development of a community-based action plan would be beneficial and cost-effective. The implementation of National Allergy Programme, a new programme designed after the success of the previous Finnish Asthma Programme in 2000 to 2010, has already shown that the burden and cost of allergic diseases can be reduced by a pragmatic public health action plan. ${ }^{53}$ A successful communitybased programme requires contributions from various stakeholders for effective implementation. Educational campaigns and networking between specialists and primary care doctors, pharmacists, nurses, teachers, parents, allergic patients, and the general public should be promoted. The treatment modalities for allergy are relatively limited at present, so prevention is the key to control this pandemic. Allergic diseases in Hong Kong and worldwide have increased dramatically in the past few decades. It is now pressing and timely to implement allergy prevention to promote a healthy lifestyle for the Hong Kong population and beyond. ${ }^{54}$

\section{Declaration}

The authors have no conflicts of interest to declare.

\section{References}

1. Pawankar R, Canonica GW, Holgate ST, Lockey RF, Blaiss MS. WAO White book on allergy: update 2013. World Allergy Organization. Available from: http://www. worldallergy.org/UserFiles/file/WhiteBook2-2013-v8.pdf. Accessed Apr 2016.

2. Zheng $\mathrm{T}, \mathrm{Yu} \mathrm{J}$, Oh $\mathrm{MH}$, Zhu Z. The atopic march: progression from atopic dermatitis to allergic rhinitis and asthma. Allergy Asthma Immunol Res 2011;3:67-73.

3. Grimshaw KE, Maskell J, Oliver EM, et al. Introduction of 
complementary foods and the relationship to food allergy. Pediatrics 2013;132:e1529-38.

4. Wong GW, Hui DS, Chan HH, et al. Prevalence of respiratory and atopic disorders in Chinese schoolchildren. Clin Exp Allergy 2001;31:1225-31.

5. Wong GW, Leung TF, Ko FW. Changing prevalence of allergic diseases in the Asia-pacific region. Allergy Asthma Immunol Res 2013;5:251-7.

6. Wong GW, Leung TF, Ma Y, Liu EK, Yung E, Lai CK. Symptoms of asthma and atopic disorders in preschool children: prevalence and risk factors. Clin Exp Allergy 2007;37:174-9.

7. Wong GW, Ko FW, Hui DS, et al. Factors associated with difference in prevalence of asthma in children from three cities in China: multicentre epidemiological survey. BM) 2004;329:486

8. Wong GW, Leung TF, Ko FW, et al. Declining asthma prevalence in Hong Kong Chinese schoolchildren. Clin Exp Allergy 2004;34:1550-5.

9. Lee SL, Wong W, Lau YL. Increasing prevalence of allergic rhinitis but not asthma among children in Hong Kong from 1995 to 2001 (Phase 3 International Study of Asthma and Allergies in Childhood). Pediatr Allergy Immunol 2004; 15:72-8.

10. Leung TF, Yung E, Wong YS, Lam CW, Wong GW. Parentreported adverse food reactions in Hong Kong Chinese pre-schoolers: epidemiology, clinical spectrum and risk factors. Pediatr Allergy Immunol 2009;20:339-46.

11. Leung TF, Yung E, Wong YS, et al. Quality-of-life assessment in Chinese families with food allergic children. Clin Exp Allergy 2009;39:890-6.

12. Ho MH, Lee SL, Wong WH, Ip P, Lau YL. Prevalence of self-reported food allergy in Hong Kong children and teens-a population survey. Asian Pac J Allergy Immunol 2012;30:275-84.

13. Wong GW, Mahesh PA, Ogorodova L, et al. The EuroPrevall-INCO surveys on the prevalence of food allergies in children from China, India and Russia: the study methodology. Allergy 2010;65:385-90.

14. Wong GW, Li J, Ma Y, et al. Comparative study of food allergy in urban and rural schoolchildren: The EuroprevallINCO Survey in China. J Allergy Clin Immunol 2011;127(2 Suppl):AB34.

15. Leung TF, Sy HY, Tsan CS, Tang MF, Wong GW. Is food allergy increasing in Hong Kong Chinese children? [abstract]. Proceedings of the 34th Congress of European Academy of Allergology and Clinical Immunology; 2015 Jun 6-10; Barcelona, Spain.

16. Kramer MS, Kakuma R. Maternal dietary antigen avoidance during pregnancy or lactation, or both, for preventing or treating atopic disease in the child. Evid Based Child Health 2014;9:447-83.

17. Bunyavanich S, Rifas-Shiman SL, Platts-Mills TA, et al. Peanut, milk, and wheat intake during pregnancy is associated with reduced allergy and asthma in children. J Allergy Clin Immunol 2014;133:1373-82.

18. Hörmannsperger G, Clavel T, Haller D. Gut matters microbe-host interactions in allergic diseases. J Allergy Clin Immunol 2012;129:1452-9.

19. Schäfer T, Bauer CP, Beyer K, et al. S3-Guideline on allergy prevention: 2014 update: Guideline of the German Society for Allergology and Clinical Immunology (DGAKI) and the German Society for Pediatric and Adolescent Medicine
(DGKJ). Allergo J Int 2014;23:186-99.

20. Muraro A, Halken S, Arshad SH, et al. EAACI food allergy and anaphylaxis guidelines. Primary prevention of food allergy. Allergy 2014;69:590-601.

21. Greer FR, Sicherer SH, Burks AW; American Academy of Pediatrics Committee on Nutrition; American Academy of Pediatrics Section on Allergy and Immunology. Effects of early nutritional interventions on the development of atopic disease in infants and children: the role of maternal dietary restriction, breastfeeding, timing of introduction of complementary foods, and hydrolyzed formulas. Pediatrics 2008;121:183-91.

22. Kramer MS. Breastfeeding and allergy: the evidence. Ann Nutr Metab 2011;59 Suppl 1:20S-26S.

23. Lack G. Update on risk factors for food allergy. J Allergy Clin Immunol 2012;129:1187-97.

24. von Berg A, Filipiak-Pittroff B, Schulz H, et al. Allergic manifestation 15 years after early intervention with hydrolyzed formulas-the GINI Study. Allergy 2016;71:210-9.

25. de Silva D, Geromi M, Halken S, et al. Primary prevention of food allergy in children and adults: systematic review. Allergy 2014;69:581-9.

26. Grimshaw KE, Maskell J, Oliver EM, et al. Diet and food allergy development during infancy: birth cohort study findings using prospective food diary data. J Allergy Clin Immunol 2014;133:511-9.

27. Nwaru BI, Erkkola M, Ahonen S, et al. Age at the introduction of solid foods during the first year and allergic sensitization at age 5 years. Pediatrics 2010;125:50-9.

28. Du Toit G, Roberts G, Sayre PH, et al. Randomized trial of peanut consumption in infants at risk for peanut allergy. $\mathrm{N}$ Engl J Med 2015;372:803-13.

29. Palmer DJ, Metcalfe J, Makrides M, et al. Early regular egg exposure in infants with eczema: A randomized controlled trial. J Allergy Clin Immunol 2013;132:387-92.e1.

30. Nordling E, Berglind N, Melén E, et al. Traffic-related air pollution and childhood respiratory symptoms, function and allergies. Epidemiology 2008;19:401-8.

31. Krämer U, Sugiri D, Ranft U, et al. Eczema, respiratory allergies, and traffic-related air pollution in birth cohorts from small-town areas. J Dermatol Sci 2009;56:99-105.

32. Accordini S, Janson C, Svanes C, Jarvis D. The role of smoking in allergy and asthma: lessons from the ECRHS. Curr Allergy Asthma Rep 2012;12:185-91.

33. Burney PG, Luczynska C, Chinn S, Jarvis D. The European Community Respiratory Health Survey. Eur Respir J 1994;7:954-60.

34. European Community Respiratory Health Survey II Steering Committee. The European Community Respiratory Health Survey II. Eur Respir J 2002;20:1071-9.

35. Tischer CG, Hohmann C, Thiering E, et al. Meta-analysis of mould and dampness exposure on asthma and allergy in eight European birth cohorts: an ENRIECO initiative. Allergy 2011;66:1570-9.

36. Iossifova YY, Reponen T, Ryan PH, et al. Mold exposure during infancy as a predictor of potential asthma development. Ann Allergy Asthma Immunol 2009;102:1317.

37. Genuneit J. Exposure to farming environments in childhood and asthma and wheeze in rural populations: a systematic review with meta-analysis. Pediatr Allergy Immunol 2012;23:509-18. 
38. Macdonald C, Sternberg A, Hunter PR. A systematic review and meta-analysis of interventions used to reduce exposure to house dust and their effect on the development and severity of asthma. Environ Health Perspect 2007;115:1691-5.

39. Lødrup Carlsen KC, Roll S, Carlsen KH, et al. Does pet ownership in infancy lead to asthma or allergy at school age? Pooled analysis of individual participant data from 11 European birth cohorts. PLoS One 2012;7:e43214.

40. Jartti T, Korppi M. Rhinovirus-induced bronchiolitis and asthma development. Pediatr Allergy Immunol 2011;22:350-5

41. Mommers M, Thijs C, Stelma F, et al. Timing of infection and development of wheeze, eczema, and atopic sensitization during the first $2 \mathrm{yr}$ of life: the KOALA Birth Cohort Study. Pediatr Allergy Immunol 2010;21:983-9.

42. Meissner HC. Economic impact of viral respiratory disease in children. J Pediatr 1994;124:S17-21.

43. Chen YC, Dong GH, Lin KC, Lee YL. Gender difference of childhood overweight and obesity in predicting the risk of incident asthma: a systematic review and meta-analysis. Obes Rev 2013;14:222-31.

44. Rzehak P, Wijga $\mathrm{AH}$, Keil $\mathrm{T}$, et al. Body mass index trajectory classes and incident asthma in childhood: results from 8 European Birth Cohorts-a Global Allergy and Asthma European Network initiative. J Allergy Clin Immunol 2013;131:1528-36.

45. Mitchell EA, Beasley R, Björkstén B, Crane J, GarcíaMarcos L, Keil U; ISAAC Phase Three Study Group. The association between BMI, vigorous physical activity and television viewing and the risk of symptoms of asthma, rhinoconjunctivitis and eczema in children and adolescents: ISAAC Phase Three. Clin Exp Allergy
2013;43:73-84.

46. de Marco R, Pesce G, Girardi P, et al. Foetal exposure to maternal stressful events increases the risk of having asthma and atopic diseases in childhood. Pediatr Allergy Immunol 2012;23:724-9.

47. Metsälä J, Lundqvist A, Virta LJ, Kaila M, Gissler M, Virtanen SM. Mother's and offspring's use of antibiotics and infant allergy to cow's milk. Epidemiology 2013;24:3039.

48. Fiocchi A, Pawankar R, Cuello-Garcia C, et al. World Allergy Organization-McMaster University Guidelines for Allergic Disease Prevention (GLAD-P): Probiotics. World Allergy Organ J 2015;8:4.

49. McKeever TM, Lewis SA, Smith C, Hubbard R. Vaccination and allergic disease: a birth cohort study. Am J Public Health 2004;94:985-9.

50. Jacobsen L , Niggemann B, Dreborg S, et al. Specific immunotherapy has long-term preventive effect of seasonal and perennial asthma: 10-year follow-up on the PAT study. Allergy 2007;62:943-8.

51. Marogna M, Spadolini I, Massolo A, Canonica GW, Passalacqua G. Long-lasting effects of sublingual immunotherapy according to its duration: a 15-year prospective study. J Allergy Clin Immunol 2010;126:969-75.

52. Roduit C, Frei R, Depner M, et al. Increased food diversity in the first year of life is inversely associated with allergic diseases. J Allergy Clin Immunol 2014;133:1056-64.

53. Haahtela T, Valovirta E, Kauppi P, et al. The Finnish Allergy Programme 2008-2018-scientific rationale and practical implementation. Asia Pac Allergy 2012;2:275-9.

54. Chan YT, Ho HK, Lai CK, et al. Allergy in Hong Kong: an unmet need in service provision and training. Hong Kong Med J 2015;21:52-60. 